\title{
Pregabalin Influences Insula and Amygdala Activation During Anticipation of Emotional Images
}

\author{
Robin L Aupperle ${ }^{* 1,2}$, Lakshmi Ravindran ${ }^{1,2}$, Dharol Tankersley', Taru Flagan', Nathan R Stein, \\ Alan N Simmons ${ }^{1,2,3}$, Murray B Stein ${ }^{1,2}$ and Martin P Paulus \\ 'Department of Psychiatry, University of California San Diego (UCSD), La Jolla, CA, USA; ${ }^{2}$ Psychiatry Service, Veterans Affairs San Diego Health \\ Care System, University of California San Diego, La Jolla, CA, USA; ${ }^{3}$ Research Service, Veterans Affairs San Diego Health Care System, University \\ of California San Diego, La Jolla, CA, USA
}

\begin{abstract}
Pregabalin (PGB) has shown potential as an anxiolytic for treatment of generalized and social anxiety disorder. PGB binds to voltagedependent calcium channels, leading to upregulation of GABA inhibitory activity and reduction in the release of various neurotransmitters. Previous functional magnetic resonance imaging ( $\mathrm{fMRI}$ ) studies indicate that selective serotonin reuptake inhibitors and benzodiazepines attenuate amygdala, insula, and medial prefrontal cortex activation during anticipation and emotional processing in healthy controls. The aim of this study was to examine whether acute PGB administration would attenuate activation in these regions during emotional anticipation. In this double-blind, placebo-controlled, randomized crossover study, 16 healthy controls completed a paradigm involving anticipation of negative and positive affective images during $\mathrm{fMRI}$ approximately I h after administration of placebo, 50, or 200 mg PGB. Linear mixed model analysis revealed that PGB was associated with (I) decreases in left amygdala and anterior insula activation and (2) increases in anterior cingulate (ACC) activation, during anticipation of positive and negative stimuli. There was also a region of the anterior amygdala in which PGB dose was associated with increased activation during anticipation of negative and decreased activation during anticipation of positive stimuli. Attenuation of amygdala and insula activation during anticipatory or emotional processing may represent a common regional brain mechanism for anxiolytics across drug classes. PGB induced increases in ACC activation could be a unique effect related to top-down modulation of affective processing. These results provide further support for the viability of using pharmaco-fMRI to determine the anxiolytic potential of pharmacologic agents.

Neuropsychopharmacology (20I I) 36, I466-1477; doi: I 0.1038/npp.20 I I.32; published online 23 March 201 I
\end{abstract}

Keywords: pregabalin; neuroimaging; insula; amygdala; anticipation; psychopharmacology

\section{INTRODUCTION}

Anxiety disorders are among the most commonly diagnosed psychiatric disorders, with an estimated prevalence of $18 \%$ in the United States (Kessler et al, 2005). The most frequently prescribed pharmacologic agents for treating anxiety are benzodiazepines and selective serotonin reuptake inhibitors (SSRIs), which are effective for $40-80 \%$ of patients depending on the disorder and the specific study (Asnis et al, 2001; Bandelow et al, 2004; Davidson et al, 1993, 2004; Hoffman and Mathew, 2008; Jorstad-Stein and Heimberg, 2009; Kasper et al, 2005; Laakmann et al, 1998; Mitte et al, 2005; Moroz and Rosenbaum, 1999; Pull and Damsa, 2008; Stein et al, 1999; Van Ameringen et al,

\footnotetext{
*Correspondence: Dr RL Aupperle, Department of Psychiatry, VA San Diego Healthcare System, University of California San Diego, 8939 Villa La Jolla Drive Suite 200, La Jolla, CA 92037-0985, USA, Tel: + 1858 534 9448, Fax: + I 858534 9450, E-mail: raupperle@ucsd.edu Received 5 October 2010; revised I February 2011; accepted 16 February 2011
}

2009). Clinicians are often hesitant to prescribe benzodiazepines because of concerns about long-term efficacy, side effects (including sedation and cognitive impairment), and potential risks for abuse or dependence (Cloos and Ferreira, 2009; McIntosh et al, 2004). Owing to their efficacy and reduced abuse liability, SSRIs are often considered first line pharmacologic treatment for anxiety (McIntosh et al, 2004). However, SSRIs are limited because of having a relatively slow onset of effects (eg, 2-4 weeks) and side effects such as sexual dysfunction or weight gain that can be of particular concern to patients (Baldwin, 2008). Considering these issues, there remains considerable room to improve both the effectiveness and side effect profile of pharmacologic anxiety treatment.

Pregabalin (PGB), currently marketed in the United States for treatment of fibromyalgia and neuropathic pain, has also shown promise as an anxiolytic. Research indicates PGB's primary mechanism of action involves binding at the $\alpha_{2} \delta$ subunit of voltage-dependent calcium channels, subsequently leading to upregulation of GABA inhibitory activity and a reduction in the release of several 
neurotransmitters, including glutamate, noradrenaline, and substance P (Brawek et al, 2008; Dooley et al, 2007; Fink et al, 2002; Gee et al, 1996). Daily doses of 100-600 mg PGB have been shown to significantly reduce anxiety symptoms for $45-60 \%$ of generalized and social anxiety disorder patients (Feltner et al, 2003, 2008; Pande et al, 2003, 2004; Pohl et al, 2005; Rickels et al, 2005). Similar to benzodiazepines, improvement is observed within 1 week following PGB treatment initiation (Feltner et al, 2003; Pande et al, 2003, 2004; Pohl et al, 2005; Rickels et al, 2005). Additionally, PGB shows less of an effect on cognitive function and sedation than alprazolam (Hindmarch et al, 2005) and discontinuation rates because of adverse events have been lower for PGB (5-20\%) than benzodiazepines (15-35\%) (Feltner et al, 2003; Lydiard et al, 2010; Rickels et al, 2005).

Functional magnetic resonance imaging (fMRI) can be used to delineate regional neural mechanisms of pharmacologic treatments and has the potential to serve as a biomarker for predicting anxiolytic function for current and novel agents (Paulus and Stein, 2007). fMRI studies with healthy controls report acute benzodiazepine administration to attenuate activation of insula, amygdala, and medial prefrontal cortex (mPFC) during paradigms involving processing of emotional faces (Paulus et al, 2005), anticipation of painful stimuli (Wise et al, 2007), and punishment during risk-based decision making (Arce et al, 2006). Sub-chronic SSRI administration (eg, 3-30 days) has been associated with decreased amygdala, insula, and/or mPFC and anterior cingulate (ACC) activation during anticipation (Simmons et al, 2009) and processing of aversive pictures (Takahashi et al, 2005) and emotional faces (Anderson et al, 2007; Arce et al, 2008; Del-Ben et al, 2005; Harmer et al, 2006; Windischberger et al, 2010). Therefore, despite unique mechanisms of action, both benzodiazepines and SSRIs may exert anxiolytic influence through a common pathway of decreasing neural responses in regions involved in emotional processing and interoceptive awareness (ie, awareness of internal bodily state).

Anticipatory anxiety is thought to be a cardinal symptom of anxiety disorders (Craske et al, 2009) and anticipation paradigms are sensitive to insula, amygdala, and PFC activation (Nitschke et al, 2006; Simmons et al, 2004) as well as to pharmacologic effects of benzodiazepines and SSRIs (Simmons et al, 2009; Wise et al, 2007). The primary aim of this study was to delineate potential neuroanatomical mechanisms of action for PGB during anticipatory processing. On the basis of the findings regarding the effects of other anxiolytic agents (eg, benzodiazepines, SSRIs), we hypothesized that PGB would be associated with attenuated activation of amygdala, insula, and $\mathrm{mPFC}$ during anticipation of emotional images. As PGB's proposed molecular mechanisms of action are unique compared with both benzodiazepines and SSRI's, this study also aimed to contribute knowledge concerning fMRI's potential as an anxiolytic biomarker across unique drug classes.

\section{PATIENTS AND METHODS}

\section{Participants and Study Design}

Sixteen right-handed, healthy volunteers (10 male; mean age $=23.2 \pm 2.6)$ participated in three scanning sessions;

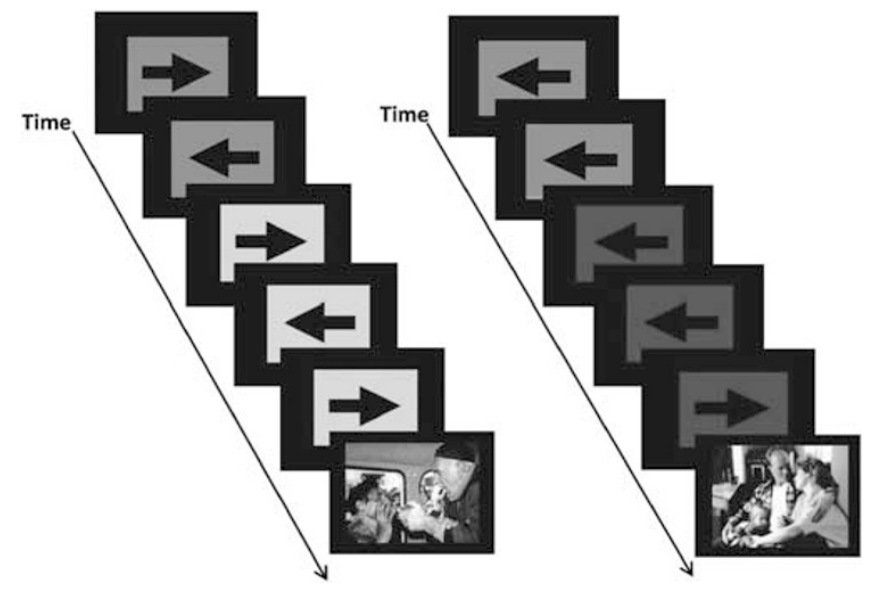

Figure I Functional magnetic resonance imaging ( $\mathrm{fMRI}$ ) anticipation task. This task combines a continuous performance task with the interspersed presentation of affective stimuli. Subjects are asked to press a left or right button based on the direction of the arrow. Subjects are instructed before the task that a blue square accompanied by a low tone indicates a positive image is going to appear. In contrast, a switch to a yellow square accompanied by a high tone signals an impending negative image. Images used in this paradigm were taken from the International Affective Picture System (IAPS) (Lang et al, 2008). The color reproduction of this figure is available on the html full text version of the manuscript

one placebo, one low dose $(50 \mathrm{mg})$ and one high dose ( $200 \mathrm{mg}$ ) of PGB, each conducted 1 to 3 weeks apart to allow for complete elimination of the drug. Sessions were pseudorandomized and double-blind. Diagnostic interviews were conducted and exclusion criteria included satisfying DSMIV criteria for an axis I psychiatric disorder, current substance abuse, neurological disorders, current medications, smoking, or excessive caffeine consumption ( $>4$ cups/day). All subjects gave written, informed consent and were treated in accordance with the Declaration of Helsinki. The study was approved by the University of California, San Diego Human Research Protection Program.

During scanning, subjects performed an anticipation task that combined a continuous performance task (CPT) with interspersed presentation of affective stimuli (see Figure 1) (Simmons et al, 2008, 2009). During the CPT, subjects pressed a 'LEFT' or 'RIGHT' button corresponding to the direction of an arrow on the screen. Simultaneously, a $250 \mathrm{~ms}$ long $500-\mathrm{Hz}$ tone was presented every $2 \mathrm{~s}$. During baseline conditions, the background was gray. Subjects were instructed that when the background turned blue, accompanied by a $250-\mathrm{Hz}$ tone, a positive image would appear, whereas when the background turned yellow, accompanied by a $1000-\mathrm{Hz}$ tone, a negative image would appear. Trials with blue or yellow background represented anticipation periods. Picture stimuli included 17 positive (ie, pleasant social scenes) and 17 negative (ie, physical injuries, common traumatic events) images from the International Affective Picture System (IAPS) (Lang et al, 2008). Positively and negatively valenced images were matched on levels of arousal (as reported in the IAPS manual) and content. No subject response was required during affective image presentation. Anticipation periods lasted $6 \mathrm{~s}$, image presentation lasted $2 \mathrm{~s}$, and the baseline CPT was interspersed for variable duration (mean $=8 \mathrm{~s}$ ) between task components. Total task duration was $580 \mathrm{~s}$. The CPT task 
was included to ensure subjects attended to the task and to provide measures of response accuracy and reaction time during the various task conditions.

Oral doses of PGB or placebo were administered with a small amount of diet coke approximately $1 \mathrm{~h}$ before scanning. Plasma concentrations were acquired after 15, 30, 75, 90, and $110 \mathrm{~min}$. Before dosing and after scanning, subjects completed the Karolinska Sleepiness Scale (KSS) with possible scores ranging from 1 to 9 (Akerstedt and Gillberg, 1990), State-Trait Anxiety Inventory (STAI) state subscale with possible scores ranging from 20 to 80 (Spielberger, 1983), and rated their current state on a $10 \mathrm{~cm}$ Visual Analog Scale (VAS) for the following dimensions: anxious, embarrassed, tense, tired, dizzy, high, nervous, and trembling.

\section{Data Acquisition}

The anticipation task was conducted during one fMRI scan sensitive to blood oxygenation level-dependent (BOLD) contrast using a Signa Excite (GE Healthcare) 3.0T scanner ( $2^{*}$-weighted echoplanar (EPI) imaging, $\mathrm{TR}=2000 \mathrm{~ms}$, $\mathrm{TE}=32 \mathrm{~ms}, 64 \times 64$ matrix, thirty $2.6 \mathrm{~mm}$ axial slices with a $1.4 \mathrm{~mm}$ gap, 290 scans). During the same session, a highresolution T1-weighted image (spoiled gradient recalled, $\mathrm{TR}=8 \mathrm{~ms}, \mathrm{TE}=3 \mathrm{~ms}, \mathrm{FOV}=25 \mathrm{~cm}$, approximately $1 \mathrm{~mm}^{3}$ voxels) was obtained for anatomical reference.

Whole-brain images sensitive to arterial spin labeling (ASL) were included to identify and covary for PGB's overall effects on cerebral blood flow (CBF) and acquired with a PICORE-QUIPSS II (Wong et al, 1998) sequence, dual-echo spiral acquisition $(\mathrm{TE} 1=3 \mathrm{~ms}, \mathrm{TE} 2=30 \mathrm{~ms}$; $\mathrm{TR}=2000 \mathrm{~ms}$, flip angle $=90^{\circ}, 3.43 \times 3.43 \mathrm{~mm}$ in-plane resolution, five $6 \mathrm{~mm}$ slices, $20 \mathrm{~cm}$ tag width, $1 \mathrm{~cm}$ gap between the tag and the proximal imaging slice, TI $=700 \mathrm{~ms}$, TI $2=1400 \mathrm{~ms}$ ). ASL scans were calibrated between subjects and scanning sessions (Floyd et al, 2003). Proton density of cerebrospinal fluid, a signal index directly proportional to that of blood and relatively consistent across both time and subjects, was obtained with a single image through the ventricles at $\mathrm{TE}=3 \mathrm{~ms}$.

\section{Data Analysis}

Data were preprocessed and analyzed using Analysis of Functional NeuroImages (AFNI) software (Cox, 1996) and R statistical packages (http://www.r-project.org). EPI images were aligned to high-resolution anatomical images and resampled to $4 \times 4 \times 4 \mathrm{~mm}$ voxel size (original $3.7 \times 3.7 \times$ $2.6 \mathrm{~mm}$ with $1.4 \mathrm{~mm}$ gap). Data were spatially blurred with a $4 \mathrm{~mm}$ FWHM spatial filter and normalized to Talairach space (via AFNI's auto Talairach program, followed by visual inspection of each image). Preprocessed individual time-series data were analyzed using a multiple regression model based on a BOLD hemodynamic response function with a 4-6s peak. Regressors of interest included four orthogonal regressors used to quantify neural activation for each task component: (1) anticipation of positive images (APIs), (2) anticipation of negative images (ANIs), (3) presentation of positive images (PIs), and (4) presentation of negative images (NIs). Five regressors of no interest were included: three motion-related regressors (roll, pitch, yaw), data from a white-matter mask (averaged at each TR) to control for physiological noise, and a regressor for linear trends to eliminate slow signal drifts. This paper focuses on results from the anticipation phase, although results from the image phase are included in Supplementary Tables S5-S7.

Percent signal change (PSC) was calculated by dividing the regressor of interest by the control regressor. PSC for API and ANI was subjected to linear mixed effects (LMEs) analysis in R (www.cran.org). Mixed effects models offer a flexible framework to model sources of variation and correlation that arise from grouped data. They are particularly robust for analysis of unbalanced data when compared with similar analyses within the general linear model framework. Implementation of LME in R estimates parameters using the maximum likelihood estimation or restricted maximum likelihood estimation procedure. Subject was treated as random effects and dose (placebo, $50 \mathrm{mg}$, $200 \mathrm{mg}$ ) and task valence (API, ANI) as fixed effects. Main and interaction effects of dose and valence were examined. Bilateral amygdala, mPFC, and insula were selected as a priori regions of interest (ROIs) based on literature implicating them in emotional processing, anticipation, and anxiety disorders. These anatomical regions were defined using Talairach Atlas (see Supplementary Figure 1) (Lancaster et al, 2000). The mPFC included ventral and dorsal ACC (including BA 32, 24) and ventromedial PFC (BA 10). The MPFC was partitioned into dorsal and ventral extents at $z=0$, and the insula was partitioned into anterior and posterior portions using linear interpolation for location of the middle insular gyrus. Thus, there were eight $a$ priori ROIs: bilateral amygdala ( $2752 \mu \mathrm{l}$ each), dorsal (21 $824 \mu \mathrm{l})$, and ventral $(17984 \mu \mathrm{l}) \mathrm{mPFC}$, bilateral anterior $(9920 \mu \mathrm{l}$ each) and posterior ( $8512 \mu \mathrm{l}$ each) insula. Whole-brain volume consisted of $2334464 \mu \mathrm{l}$. A threshold adjustment method based on Monte-Carlo simulations (conducted via AFNI's program Alpha Sim) was used to guard against identifying false-positive areas of activation (considering region voxel size, $4 \mathrm{~mm}$ smoothness, and 0.05 $p$ threshold). This resulted in the following minimum cluster volumes to be considered significant: $192 \mu \mathrm{l}$ for amygdala, $256 \mu \mathrm{l}$ for insula regions, $320 \mu \mathrm{l}$ for $\mathrm{mPFC}$ regions, and $832 \mu \mathrm{l}$ for whole-brain analyses. Although the cluster significance of $p<0.05$ (two-tailed) was used for all analyses, corrected voxel-wise probabilities were: amygdala $p<0.0021$, anterior insular $p<0.0015$, posterior insula $p<0.0016$, $\mathrm{mPFC}$ regions $p<0.0008$, and whole-brain $p<0.00001$. All reported coordinates are peak-voxel Talairach coordinates $(x, y, z)$ and labeled based on visual observation and Talairach Daemon software (Lancaster et al, 2000). For identified activation clusters, average PSC was extracted and F and $p$-values for the LME were calculated. To further characterize main and interaction effects, post hoc LMEs were conducted with specific contrasts (eg, PLB vs $50 \mathrm{mg}$, PLB vs $200 \mathrm{mg}, 50$ vs $200 \mathrm{mg}$ ), considered significant at $p<0.05$. Notably, although clusters exhibiting a main effect were not significant for the interaction, there were subregions of the same ROIs exhibiting both main and interaction effects.

Behavioral data (CPT reaction time and accuracy) were subjected to LME analyses with subject as random effects and PGB dose and task valence as fixed effects. Survey data (KSS, STAI, and VAS scales) were subjected to LME 
analyses with subject as random effects and PGB dose and time of self-report (before dosing $v s$ post-scan) as fixed effects to examine dose by time interactions. To further characterize identified effects, post hoc LMEs were conducted with specific contrasts (eg, PLB vs $50 \mathrm{mg}$, PLB vs $200 \mathrm{mg}, 50 v s 200 \mathrm{mg}$ ), considered significant at $p<0.05$. Voxel-based fMRI analyses were conducted with the addition of behavioral covariates (difference score between pre-dosing and post-scan) significantly influenced by PGB dose. Any changes these covariates made to fMRI ROI results are discussed.

PGB plasma concentrations were assessed at National Medical Services Lab using high-performance liquid chromatography. The detection limit of this procedure is $0.10 \mathrm{mcg} / \mathrm{ml}$. LME analysis was conducted with subject as random effects and PGB dose and time of blood drawn as fixed effects to examine dose by time interaction effects on plasma concentration.

ASL scans were reconstructed and CBF was calculated using in-house MATLAB scripts (Rack-Gomer et al, 2009). Voxel-based LMEs were completed in $\mathrm{R}$ to examine potential drug effects on CBF. Whole-brain and anatomically constrained ROI analyses were conducted with these results as described for BOLD data. Voxel-based fMRI LME analysis was also conducted with $\mathrm{CBF}$ as a covariate and any changes this made to fMRI ROI results are discussed.

\section{RESULTS}

\section{Behavior}

Post-medication dizziness and KSS ratings were missing for one subject and there were two individual scans in which CPT behavioral data did not save correctly. All other behavioral data were available for the 16 subjects at each of the three scans. Degrees of freedom for each analysis are reflective of the number of data points available for that measure. Supplementary Table S1 displays the mean and SD for behavioral variables for each dose and time of measurement.

LME modeling revealed a significant dose by time (pre-dosing $v s$ post-scan) effect on ratings of sleepiness (KSS; $\mathrm{F}(2,72)=3.30, p=0.043$; post hoc analyses revealed $(\mathrm{PLB}=50 \mathrm{mg})<200 \mathrm{mg}$ ) and VAS ratings of feeling dizzy $(\mathrm{F}(2,73)=10.60, \quad p<0.001$; post hoc analyses revealed $(\mathrm{PLB}=50 \mathrm{mg})<200 \mathrm{mg})$, trembling $(\mathrm{F}(2,73=3.74, p=0.028$; post hoc analyses revealed $50<200 \mathrm{mg})$, high $(\mathrm{F}(2,72=3.19$, $p=0.047$; post hoc analyses revealed $\mathrm{PLB}<200 \mathrm{mg}$ ), and tired $(\mathrm{F}(2,73=3.13, p=0.050$; post hoc analyses revealed $50<200 \mathrm{mg}$ ). See Figure 2 for graphical presentation of these results. Dose had no significant effect on pre-dosing $v s$ postscan ratings of state anxiety (STAI state subscale; $\mathrm{F}(2,73)=$ 2.52, $p=0.088$, nonsignificant effect was related to STAI score increasing slightly more at the $200 \mathrm{mg}$ dose sessions as compared with the $50 \mathrm{mg}$ dose, but not as compared with placebo), or VAS ratings related to feeling embarrassed $(\mathrm{F}(2,73)=1.54, p=0.220)$, nervous $(\mathrm{F}(2,73)=1.08$, $p=0.350)$, anxious, or tense $(\mathrm{Fs}<1)$.

LMEs analyses also revealed a significant effect of dose on CPT reaction time $(\mathrm{F}(2,114)=10.40, p<0.001$; post hoc analyses revealed (PLB $=50 \mathrm{mg})<200 \mathrm{mg}$ ) and accuracy $(\mathrm{F}(2,114)=5.76, \quad p=0.004$; post hoc analyses revealed
$(\mathrm{PLB}=50 \mathrm{mg})<200 \mathrm{mg})$. See Figure 2 for graphical representation of these effects. The main effect of valence and the dose by valence interaction effect were not significant (dose by valence effect on reaction time, $F(4,114)=1.09$, $p=0.363$, all other Fs $<1$ ).

Although dose influenced both subjective ratings and CPT performance, the subjective measures (KSS, STAI, VAS ratings) were not significantly correlated with valence aspects of CPT performance (accuracy, reaction time).

\section{Plasma Concentration}

Plasma concentrations were elevated throughout the scanning phase for the $200 \mathrm{mg}$ dose (mean concentration for $30-120 \mathrm{~min}$ post-administration $=4.68 \pm 1.59 \mathrm{SD}$ ) and were near the detectable limit for the $50 \mathrm{mg}$ dose (mean concentration $30-120 \mathrm{~min}$ post-administration $=1.27 \pm 0.41$ ). LME analyses revealed significant effects of dose $(\mathrm{F}(1,116)=$ $250.33, p<0.001)$, time $(\mathrm{F}(4,116)=14.55, p<0.001)$, and dose by time interaction $(\mathrm{F}(4,116)=11.69, p<0.001)$, reflecting that greater dose was associated with greater plasma concentration levels, that concentration levels increased with time, and that there was a greater increase in plasma concentration levels for the $200 \mathrm{mg}$ than the $50 \mathrm{mg}$ dose (see Figure 3).

\section{fMRI}

Task-valence effects. ROI analysis revealed main effects of valence within the left $(960 \mu \mathrm{l}, \mathrm{F}(1,75)=18.60, p<0.005$; $-24,-4,-26)$ and right $(192 \mu \mathrm{l}, \mathrm{F}(1,75)=9.83, p<0.005$; $38,-8,-22)$ amygdala (Figure 4$)$, and left $(832 \mu \mathrm{l}$, $\mathrm{F}(1,75)=14.69, p<0.001 ;-32,-16,18)$ and right $(320 \mu \mathrm{l}$, $\mathrm{F}(1.75)=9.43, p<0.005 ; 36,-20,18)$ posterior insula, which were driven by greater activations for API than ANI regardless of PGB dose. One region of the right anterior/ middle insula $(256 \mu \mathrm{l}, \mathrm{F}(1,75)=11.26, p<0.005 ; 36,8,-2)$ exhibited greater activation for ANI than API (see Figure 4). No activations within the mPFC/ACC met criteria for significance. Results from whole-brain analysis of valence main effects are included in Supplementary Table S2 and include the left amygdala and posterior insula regions identified during ROI analyses as well as regions of the cortex that exhibited greater activation for either API (eg, dorsomedial PFC and superior PFC (BA 6), posterior cingulate, inferior and superior temporal) or ANI (eg, superior PFC (BA 6), dorsolateral PFC (BA 9), occipital, and superior temporal). When the LME valence analyses was constrained to placebo scans only, results remained similar for both ROI and whole-brain analyses as compared with the valence main effect across groups, although the right anterior insula ROI no longer met the cluster threshold (192 $\mu \mathrm{l}$ as compared with $256 \mu \mathrm{l}$; see Supplementary Table S3).

Dose effects. ROI analysis revealed dose to be associated with decreases in activation (for API and ANI) within left amygdala $(640 \mu \mathrm{l}, \mathrm{F}(2,75)=11.06, p<0.001,-28,-4,-14$; post hoc $t$-test, $p<0.05$, (PLB $=50 \mathrm{mg})>200 \mathrm{mg})$ and left $(384 \mu \mathrm{l}, \mathrm{F}(2,75)=5.23, p=0.007,-32,8,14$; post hoc $t$-test, $p<0.05, \quad$ PLB $>(50 \mathrm{mg}=200 \mathrm{mg}))$ and right $(320 \mu \mathrm{l}$, $\mathrm{F}(2,75)=4.86, p=0.01,28,20,14$; post hoc $t$-test, $p<0.05$, $\mathrm{PLB}>(50 \mathrm{mg}=200 \mathrm{mg})$ ) anterior insula (see Figure 5). 

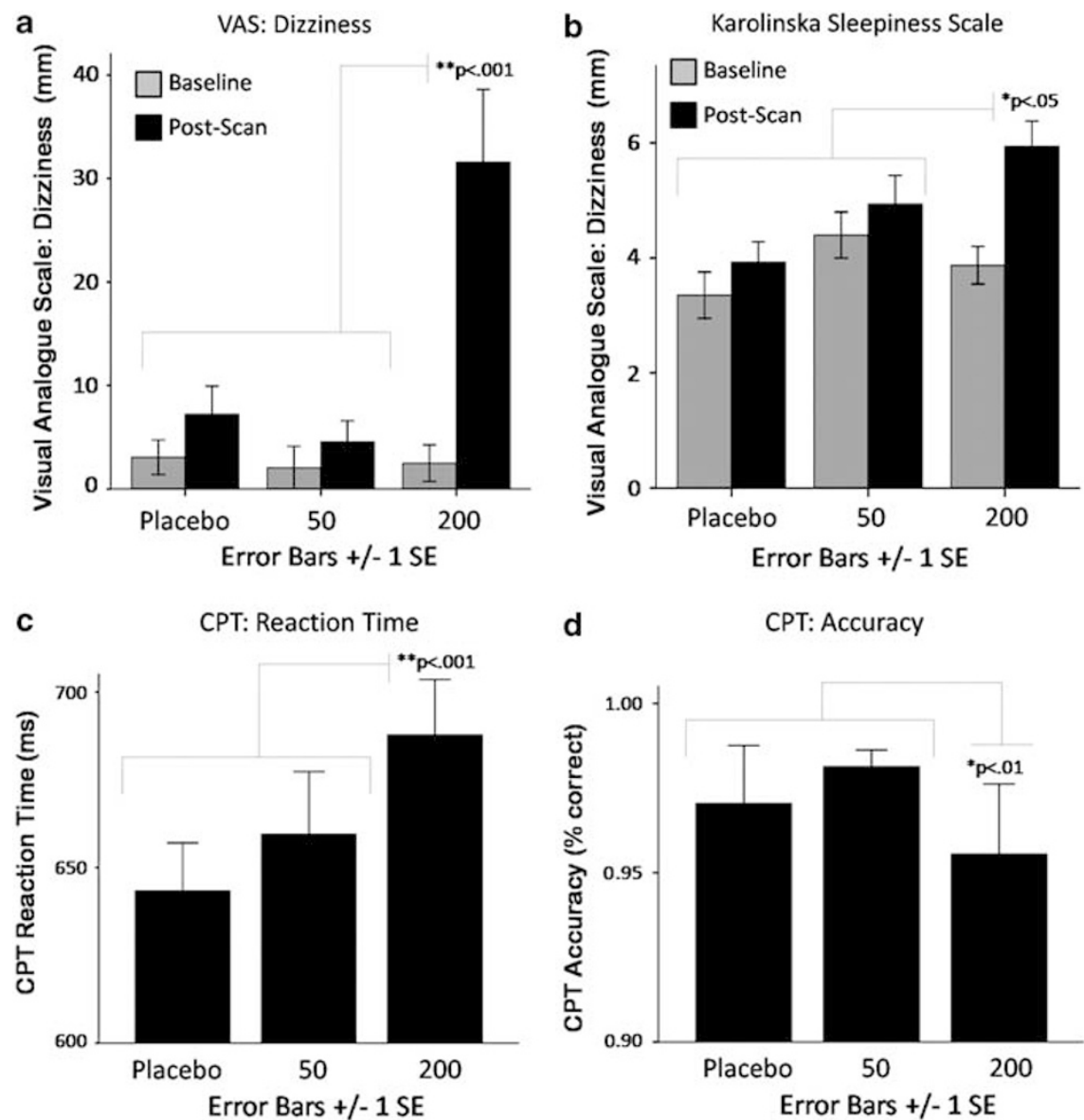

Figure 2 Pregabalin (PGB) dose effect on self-report and behavioral measures. PGB exhibited dose effects on self-report measures related to (a) increased dizziness as measured by visual analogue scale (post hoc tests revealed $(0=50)<200$ ), (b) increased sleepiness as measured by the Karolinska Sleepiness Scale (KSS; Akerstedt and Gillberg, 1990; post hoc tests revealed $(0=50)<200)$. PGB also exhibited effects on performance during the continuous performance task (CPT; averaged across conditions) conducted during the functional magnetic resonance imaging ( $\mathrm{M} M \mathrm{RI}$ ) anticipation paradigm, including (c) increased reaction time (post hoc tests revealed $(0=50)>200$ ) and (d) decreased accuracy (post hoc tests revealed $(0=50)<200)$.

There was also a dose-effect of increased activation in mid ACC (ACC, BA 32; $512 \mu \mathrm{l}, \mathrm{F}(2,75)=6.02, p<0.005,16$, $36,-2$; post hoc $t$-test, $p<0.05$, (PLB $=50 \mathrm{mg})>200 \mathrm{mg}$; see Figure 5). Post hoc analyses of these effects suggested that insula attenuation was observed for both the 50 and $200 \mathrm{mg}$ dose compared with placebo (but no differences between doses), while activation within amygdala and ACC were significantly different from placebo only at the $200 \mathrm{mg}$ dose. Results from whole-brain analysis of dose main effects are included in Supplementary Table S4 and include decreased activations within regions of the lateral PFC (BA 6, 8), dorsal cingulate (BA 24), superior temporal, amygdala, thalamus, and fusiform gyrus, and enhanced activation within middle frontal (BA 3, 6), and dorsal cingulate and caudate. Of note, none of the clusters listed as showing a main effect of dose (within ROI or whole-brain analyses) exhibited a significant interaction effect ( $F$ values for the interaction effect for each region observed for the dose main effect are also displayed in Supplementary Table S4). However, there were subregions of these same ROIs that did in fact exhibit interaction effects, as discussed below.
Dose $\times$ valence effects. ROI analysis: dose by valence interaction effects were evident within subregions of the left amygdala $(512 \mu \mathrm{l}, \mathrm{F}(2,75)=9.31, p<0.005,-24,4,-18$, post hoc LME: PLB $>50 \mathrm{mg}>200 \mathrm{mg}$ ) and ventral ACC (vACC; $320 \mu \mathrm{l}, \mathrm{F}(2,75)=7.93, p<0.005,-4,24,-10$, post hoc LME: $(\mathrm{PLB}=50 \mathrm{mg})>200 \mathrm{mg})$. Activation within the amygdala was driven by increased activations for ANI (ANI only $\mathrm{F}(2,30)=3.23, p=0.054)$ and decreased activations for API (API only $\mathrm{F}(2,30)=6.33, p=0.005$ ) with each successive increasing dose, while activation within the vACC was characterized by increased activations for ANI (ANI only $\mathrm{F}(2,30)=3.00, p=0.065)$ and decreased activations for API (API only $\mathrm{F}(2,30)=4.56, p=0.019)$ at the $200 \mathrm{mg}$ dose as compared with both PLB and the $50 \mathrm{mg}$ dose. These activation clusters are displayed in Figure 6. Although there were also amygdala and ACC regions exhibiting dose main effects, it is important to note that these were not the same clusters as those identified for the interaction effect. The interaction effect within the amygdala was more anterior than that identified in the main effect analyses, and the interaction effect within the ACC was more ventral than that identified in the dose main effect analyses. Whole-brain 


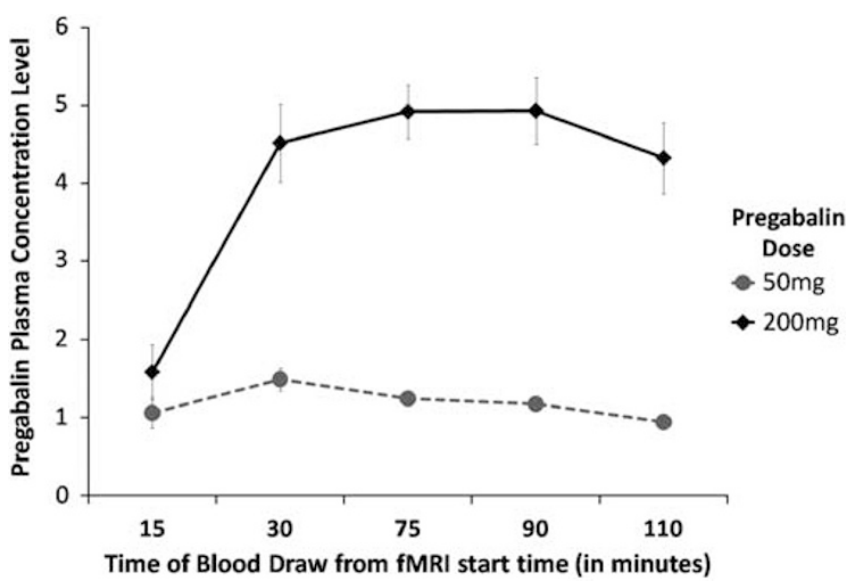

Figure 3 Pregabalin plasma concentration levels at various time points during functional magnetic resonance imaging (fMRI) scanning. Plasma was assessed at National Medical Services Lab using high-performance liquid chromatography. Both 50 and $200 \mathrm{mg}$ was associated with detectable plasma concentration levels and greater dose was associated with significantly greater concentration levels.

a
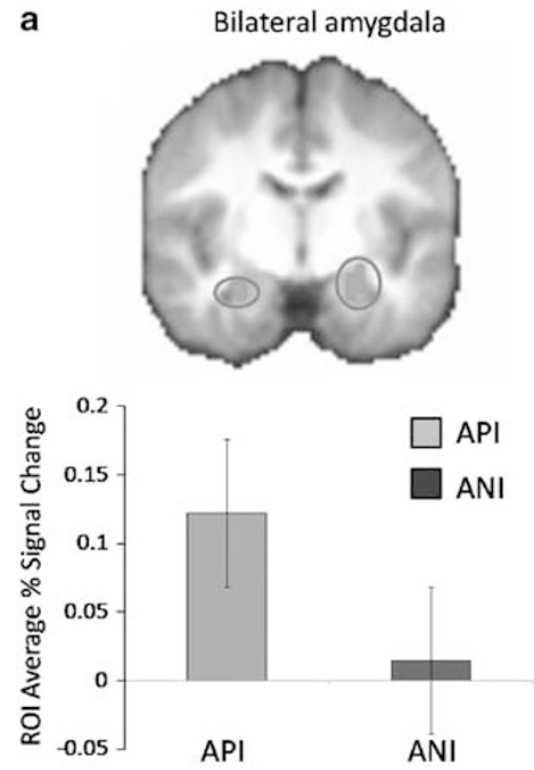

Error Bars +/- $1 \mathrm{SE}$

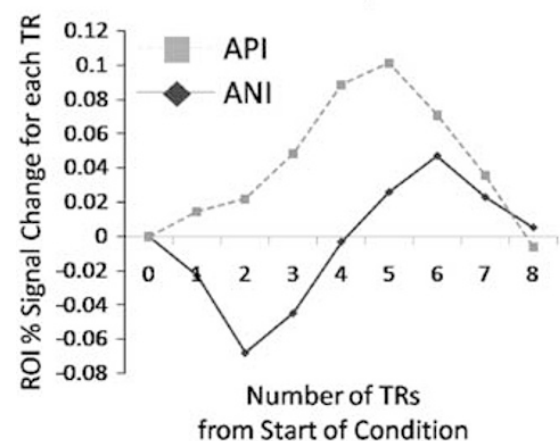

analysis revealed no clusters meeting the specified criteria of significance.

ASL. ROI linear mixed model analysis revealed that PGB increased CBF within the left vACC $(\mathrm{F}(2,24)=6.803$, $p<0.005,-12,40,2$; post hoc test revealed PLB $>50 \mathrm{mg}$ ). No significant effects of dose were found for other ROIs or for the whole-brain analyses. When CBF was included as a covariate in the fMRI analyses described above, results remained largely unchanged. For the dose main effect analysis, the reported right anterior insula cluster no longer met the cluster threshold. For the dose by valence interaction analyses, the reported vACC cluster was no longer significant. All other results remained unchanged.

Covariate analyses. The fMRI LME analyses described above were conducted to also include specific behavioral variables shown to be influenced by PGB dose as covariates, including sleepiness (KSS score), dizziness (as this was the VAS scale most influenced by PGB dose), and $\mathrm{CPT}$ reaction time (as this was the CPT measure most

b
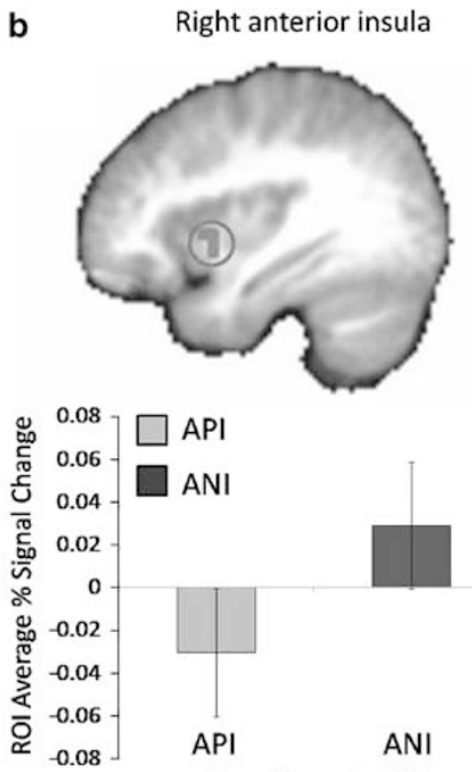

$\mathrm{API}$

Error Bars +/- 1 SE

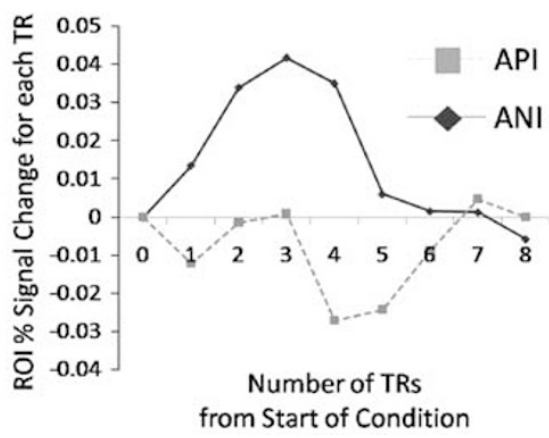

Figure 4 Task valence effect on functional magnetic resonance imaging ( $\mathrm{fMRI}$ ) blood oxygenation level-dependent (BOLD) activation. Main effects for valence of anticipation, regardless of PGB dose, were observed for (a) bilateral amygdala (shown at $y=-8$ ), which exhibited less activation (\% signal change) for negative anticipation (ANI) than positive anticipation (API) and (b) right anterior insula (shown at $x=36$ ), which exhibited greater activation for ANI than API. Graphs depicted below each image represent (I) average percent signal change (PSC) for each condition and (2) average PSC from the start of the anticipation conditions at each TR time point for each condition. 
a

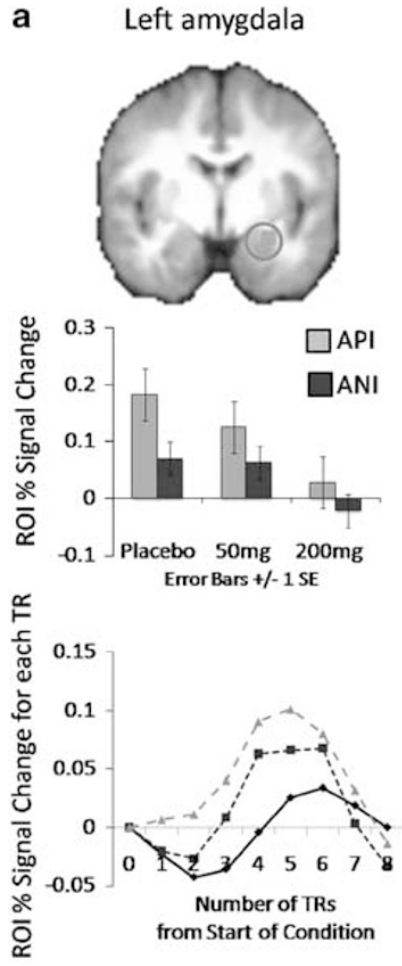

b Right anterior insula
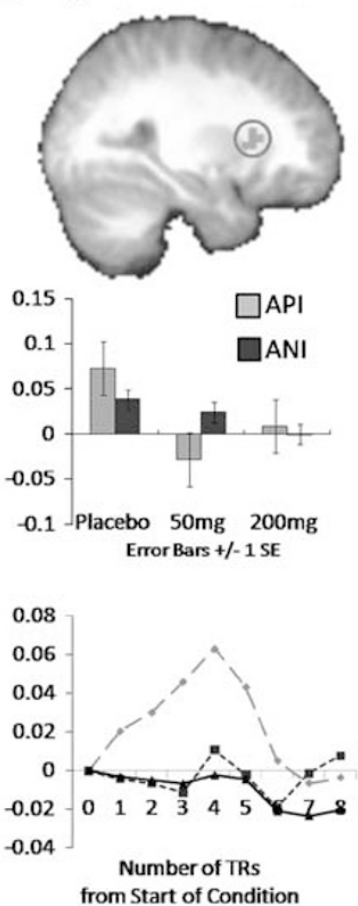

c
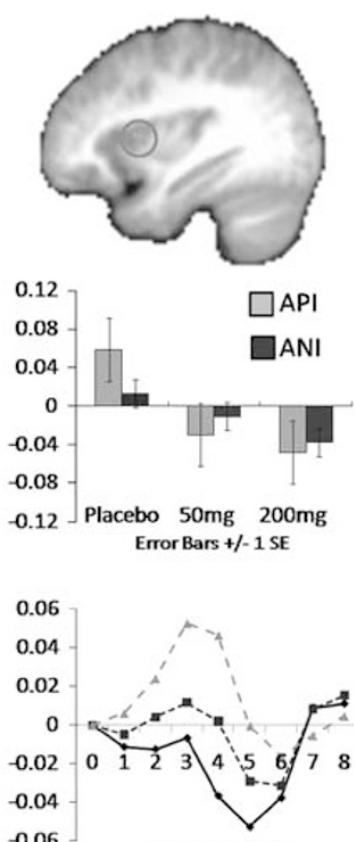

Number of TRs

from Start of Condition
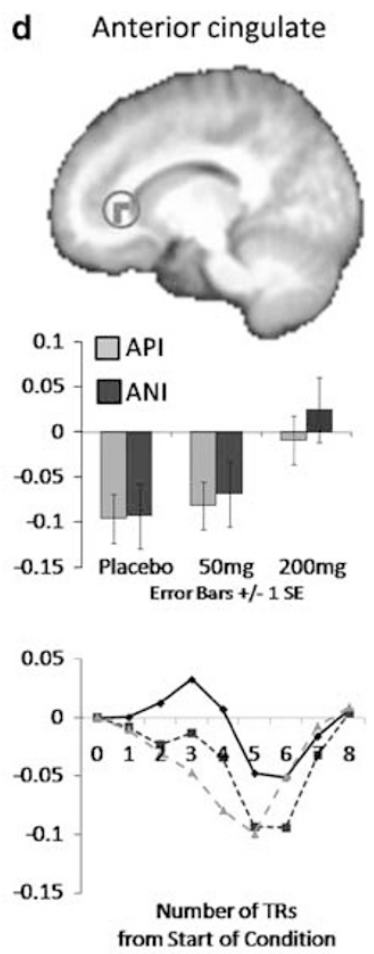

$\triangle$ Placebo $\square 0 \mathrm{mg}-200 \mathrm{mg}$

Figure 5 Pregabalin (PGB) dose effect on functional magnetic resonance imaging ( $\mathrm{MRRI}$ ) blood oxygenation level-dependent (BOLD) activation. PGB attenuated activation within in (a) left amygdala (shown at $y=4$; post hoc tests revealed (PLB=50 mg) $>200 \mathrm{mg}$ ) and (b, c) bilateral anterior insula (right insula/claustraum shown at $x=28$ and left insula shown at $x=-34$; post hoc tests revealed PLB $>(50 \mathrm{mg}=200 \mathrm{mg})$ ) and increased activation in (d) anterior cingulate (ACC; shown at $x=14$; post hoc t-tests revealed (PLB=50 mg) $>200 \mathrm{mg}$ ), for anticipation of negative (ANI) and positive images (API). Graphs depicted below each image represent (I) average percent signal change (PSC) for each condition and (2) average PSC from the start of the anticipation conditions at each TR time point for each PGB dose (averaged across negative and positive conditions).

influenced by PGB dose). When change in KSS sleepiness score (pre-medication to post-scan) was included as a covariate, all ROI results discussed above, for both dose main effect and dose by valence interaction effects, remained unaltered. When change in dizziness ratings (baseline to post-scan) was included as a covariate, all ROI dose main effects discussed above remained unaltered. For the interaction (dose by valence) analysis, the vACC cluster no longer met significance. When CPT reaction time was included as a covariate, the right anterior insula cluster reported above regarding PGB dose main effect no longer met significance. Additionally, for the interaction (dose by valence) analysis, the vACC cluster no longer met significance. All other ROI results remained unaltered.

The fMRI LMEs analyses were also conducted with session as a covariate in order to establish whether order effects accounted for the ROI results. When session was included as a covariate in the analyses, all ROI results reported above for the valence main effect remained unaltered. For the dose main effect, the right anterior insula cluster observed was no longer significant, while all other ROI results remained unaltered. For the dose by valence interaction analyses, the observed vACC no longer exceeded the cluster threshold, while the amygdala ROI remained significant.

\section{DISCUSSION}

\section{PGB fMRI Effects}

In this study, PGB exhibited attenuation of left anterior insula and left amygdala activation during ANIs and APIs. Attenuation of insula activation during anticipation of painful or emotional stimuli has previously been reported for the benzodiazepine, midazolam (Wise et al, 2007) and the SSRI, escitalopram (Simmons et al, 2009). To our knowledge, this is the first study to report amygdala attenuation by an anxiolytic during an anticipation paradigm. However, amygdala attenuation has been reported for the benzodiazepine, lorazepam (Paulus et al, 2005) and the SSRIs, citalopram, and escitalopram (Arce et al, 2008; Windischberger et al, 2010) during processing of emotional faces. Benzodiazepines are thought to exert anxiolytic effects through modulation of GABAergic neurotransmission (Atack, 2003), SSRIs are thought to exert effects primarily through modulation of the $5 \mathrm{HT}$ system (Vaswani et al, 2003), and PGB is thought to influence multiple neurotransmitters through its binding to $\alpha_{2} \delta$ subunits of calcium channels (Fink et al, 2002; Gee et al, 1996). Despite their unique neuronal mechanisms of action, evidence collected from the current and previous studies suggests they may share a common regional brain mechanismnamely, the attenuation of insula and/or amygdala 
a
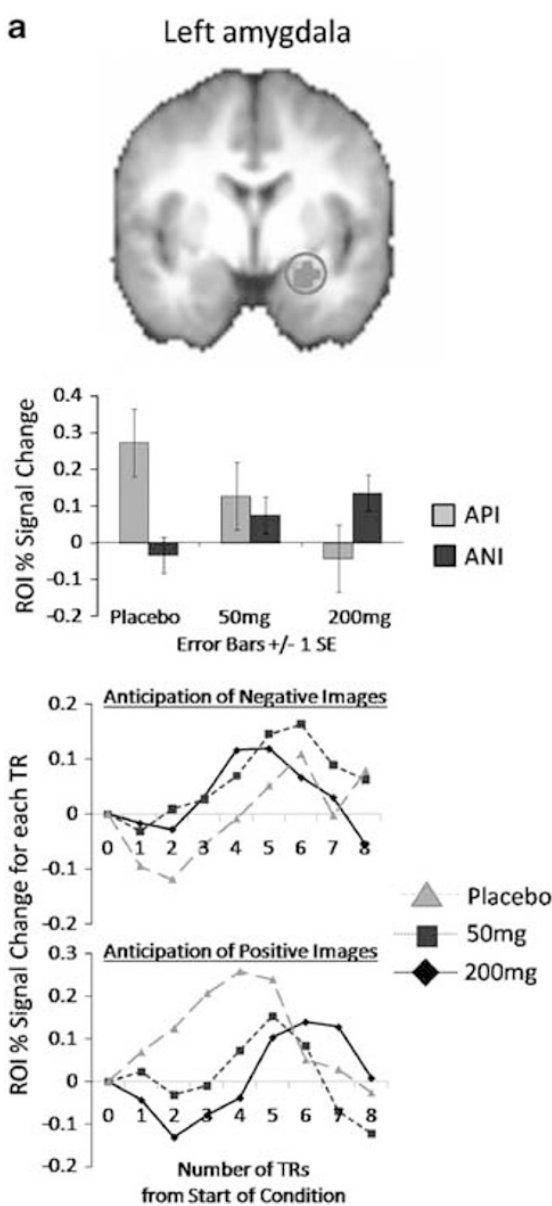

b
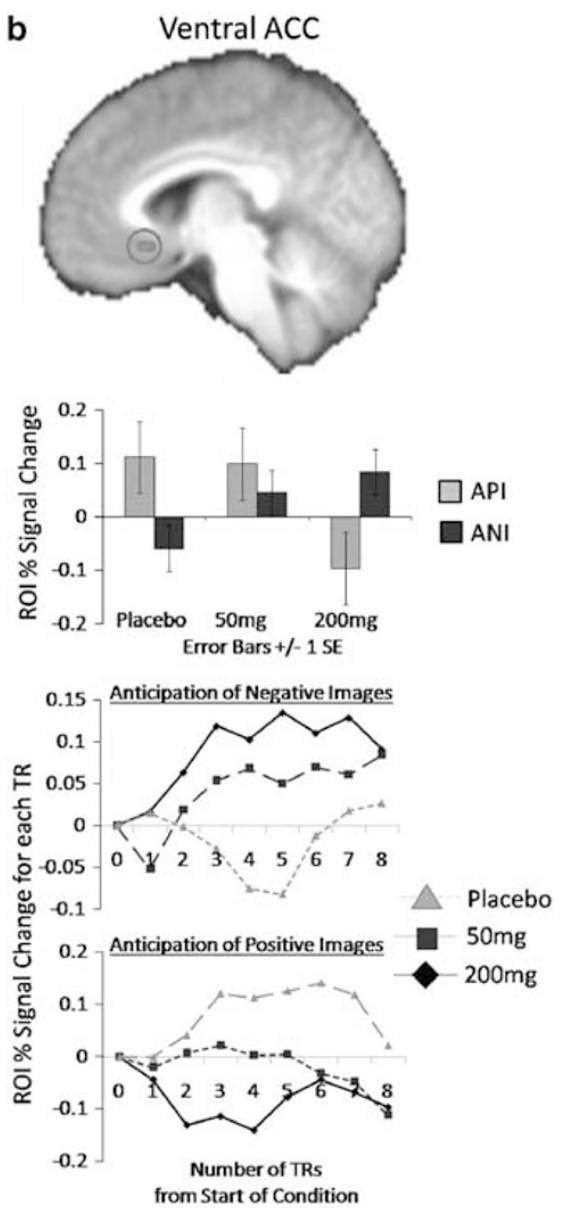

Figure 6 Pregabalin (PGB) dose $\times$ valence interaction effect on functional magnetic resonance imaging ( $\mathrm{fMRI}$ ) blood oxygenation level-dependent (BOLD) activation. Increasing PGB dose was associated with increased activation to anticipation of negative (ANI) images and decreased activation to anticipation of positive images (API) within the (a) left amygdala (shown at $y=2$; post hoc tests revealed PLB $>50 \mathrm{mg}>200 \mathrm{mg}$ ) and (b) ventral ACC (shown at $x=3$; post hoc tests revealed $(P L B=50 \mathrm{mg})>200 \mathrm{mg}$ ). Graphs depicted below each image represent (I) average percent signal change (PSC) for each condition and (2) average PSC from the start of the anticipation conditions at each TR time point for ANIs and APIs for each PGB dose.

activation during anticipatory and emotional processing. This effect may therefore represent a viable biomarker for detecting anxiolytic effects of current and novel agents that is generalizable across various drug classes. Future research could further test this hypothesis by using fMRI to investigate the neural effects of novel agents that have shown initial promise as anxiolytics in preclinical trials, such as NK1 or CRF1 receptor antagonists, or agents targeting the endocannabinoid system (Christmas et al, 2008; Hill and Gorzalka, 2009).

Although the amygdala is thought to be important for processing stimuli that are emotionally salient or that have reinforcement value (Davis and Whalen, 2001; Morrison and Salzman, 2010), the insula is considered important in interoceptive, or somatosensory, processing and is thought to be involved in calculating a 'change signal' representing the difference between current internal state and future predicted internal state (Craig, 2009; Critchley et al, 2004). Attenuation of these regions could represent a decrease in emotional responsiveness to upcoming stimuli, or modified expectations of future internal bodily state changes (Lovero et al, 2009; Strigo et al, 2010a). If such attenuation is not unique to negatively valenced situations, it suggests that PGB could potentially dampen not only negative anticipatory emotions (eg, anxiety) but also positive (eg, excitement). However, clinical trials have not reported such affective blunting, and have in some cases reported PGB to produce feelings of euphoria (Pohl et al, 2005). Future fMRI research investigating PGB's effect on individual subjective responses to emotional situations and the relationship of such effects to amydala and insula activations could help clarify the specific meaning for PGB's attenuation of these regions across anticipation conditions.

An additional finding within the amygdala was the dose by valence interaction effect, which revealed PGB to produce enhanced activation of left amygdala during ANIs compared with relative attenuated activation during APIs. This finding is opposite of most studies that have reported valence-specific effects of anxiolytic medications (Anderson et al, 2007; Del-Ben et al, 2005; Wise et al, 2007). As discussed below, general task effects for the current paradigm revealed amygdala activations greater for anticipation of positive than negative anticipation. Regardless of the reason for this pattern of amygdala activation in response to the task (discussed further below), it seems PGB may have a greater effect on amygdala activation 
during events corresponding to greater amygdala activation at baseline. Notably, the amygdala region in which PGB exhibited this differential influence for anticipation of positive $v s$ negative anticipation was more anterior than the amygdala region in which PGB exhibited a main effect across both negative and positive anticipation. Previous research has identified subregions of the amygdala that may serve different functions during emotional processing and fear learning, such as the basolateral amygdala being more involved in the evaluation of salient sensory information and the influence of other amygdala nuclei while the central amygdala may be more involved in the subsequent production of behavioral and autonomic responses to anxiety through its connections with the midbrain and brainstem (Davis and Whalen, 2001; Rosen, 2004). As these distinctions relate more to lateral $v s$ medial or dorsal $v s$ ventral subregions, it is difficult to interpret the meaning for different effects of PGB on posterior $v s$ anterior amygdala, although it raises the possibility that PGB's effect on the amygdala may depend on the specific subregion.

This study also found PGB to increase ACC activation during anticipatory processing (across both negative and positive conditions). Although there was also a region of the vACC that exhibited a dose by valence interaction effect, this cluster was no longer significant when covarying for various behavioral or clinical measures (eg, continuous performance reaction time, VAS dizziness ratings) or session order. Therefore, our discussion of PGB effects on the ACC focus on the main effect within the mid ACC (BA 32). The direction of this finding was somewhat unexpected, given that previous studies with other anxiolytics have reported either no modulation or attenuated activation of ACC (Arce et al, 2008; Simmons et al, 2009; Wise et al, 2007). MPFC and ACC regions have been implicated as primary loci for automatic regulation of limbic activation and emotional responses (Phillips et al, 2003). Therefore, enhanced ACC activation could represent increased top-down regulation during anticipatory processing. Although this finding should be considered preliminary until further replication, it suggests that enhanced ACC activation may be a unique effect of PGB.

Post hoc analysis revealed that the majority of clusters identified through whole-brain analysis (as well as the dose main effects within the amygdala and ACC) were associated with significant activation differences at the $200 \mathrm{mg}$, but not the $50 \mathrm{mg}$, dose of PGB. Previous studies support the notion that $200 \mathrm{mg}$ doses of PGB are effective in the treatment of anxiety (Feltner et al, 2003; Pohl et al, 2005), whereas doses of $50-150 \mathrm{mg}$ have been associated with minimal clinical benefit (Feltner et al, 2003; Pande et al, 2004). The fact that the $200 \mathrm{mg}$ dose seemed to be driving many of the fMRI BOLD effects observed during anticipation could therefore be considered consistent with findings from clinical research. It seems that while the $200 \mathrm{mg}$ dose was associated with increased side effects as compared with both placebo and the $50 \mathrm{mg}$ dose, the $50 \mathrm{mg}$ dose may not influence brain activation patterns (or clinical symptoms) to the same extent as the $200 \mathrm{mg}$ dose. Of note, both the 50 and $200 \mathrm{mg}$ dose were associated with dose main effects in the anterior insula and interaction effects within the amygdala. This suggests that although $50 \mathrm{mg}$ may be a subclinical dose and have less of a widespread effect on brain activation during anticipation, it may still exert subtle effects that can be identified using fMRI.

\section{PGB Behavioral Effects}

This study found PGB (particularly the $200 \mathrm{mg}$ dose) to influence subject ratings of dizziness, sleepiness, feeling high, and trembling, as well as objective measures of reaction time and accuracy during the fMRI CPT. These findings support previous research, as studies have shown PGB to often produce side effects of dizziness and drowsiness (Bandelow et al, 2004; Pande et al, 2003, 2004; Rickels et al, 2005) and to mildly influence some measures of cognitive function (Hindmarch et al, 2005; Salinsky et al, 2010). Although the cognitive effects of PGB reportedly pale in comparison with alprazolam (Hindmarch et al, 2005), further investigation of PGB's effects on cognitive function and speed of processing are warranted. Notably, current fMRI results remained largely unaltered when including behavioral and self-report measures as covariates, suggesting that findings related to PGB effects on brain activations were above and beyond what could be accounted for by changes in alertness or cognitive functioning.

\section{Anticipatory Task Effects}

In this study, the right anterior insula exhibited greater activation for anticipation of negative than positive affective images, regardless of PGB dose. This finding supports previous studies suggesting the anterior insula as important for negatively valenced anticipation (Nitschke et al, 2006; Simmons et al, 2004). However, current results also found the amygdala to exhibit greater activation for anticipation of positive than negative images. Previous healthy control studies involving anticipatory processing have either not observed significant differences in anticipatory valence within the amygdala (Simmons et al, 2004) or reported greater activation for negative than neutral anticipation (Nitschke et al, 2006). Although the amygdala is often considered important for negative emotional states, there is evidence that it most likely has a role in processing saliency of stimuli, rather than valence per se (Anderson et al, 2003; Garavan et al, 2001; Lewis et al, 2007; Small et al, 2003). The fact that the positively and negatively valenced IAPS images used in this study were match for level of arousal and that the positive images included people and scenery, which are potentially more salient than images of inanimate objects, as was used by Nitschke et al (while Simmons et al did not include a comparison anticipatory condition) could have contributed to this finding. However, this factor would not necessarily account for greater activation during anticipation of positively valenced stimuli. A recent study found that during anticipation of painful stimuli amygdala activation decreased when subjects completed a CPT as compared with passive viewing during anticipation periods (Strigo et al, 2010b). The CPT was included with the current anticipation paradigm to assure that subjects were attending to the task and looking at the screen, as well as to provide measures of response accuracy and reaction time during the different task conditions. However, it is possible that the inclusion of a cognitive task such as the CPT results in greater decrease in amygdala activation during negative $v s$ 
positive anticipatory states, therefore contributing to the pattern of amygdala activation observed in this study. The effect of including a cognitive task such as the CPT with emotional paradigms could result in the reallocation of attentional resources or provide an implicit distraction from the emotional task. The influence of cognitive tasks on neural activation patterns during emotional (negative and positive) anticipation warrants further investigation. Additionally, studies investigating PGB effects during emotional tasks that do not also involve an attentional task would help to clarify whether the results observed in this study are specific to this CPT-anticipation task or are relevant for emotional processing in general.

As apparent from the results of whole-brain analyses, the anticipation task used in this study was related to differential activation in regions other than a priori ROIs, including regions of the prefrontal, temporal, and occipital cortices. This lack of specificity is similar to that found in previous studies using this same task (Simmons et al, 2009) or other emotional processing tasks, such as that including emotional images or faces (Britton et al, 2006; Fusar-Poli et al, 2009) and suggests that a network more extensive than limbic and mPFC are involved in processing of emotional stimuli and events. The identification of tasks that more specifically activate insula and amygdala regions may prove more useful in characterizing anxiolytic potential of pharmacologic agents. However, results from this study suggest that fMRI tasks that are currently available, even given lack of specificity, may still prove useful in this regard. It is possible that regardless of the specific patterns of activation in cortical regions, the end product of attenuated insula and amygdala activation during emotional processing may represent a biomarker of anxiolytic potential.

\section{Limitations}

This study included two doses of PGB (50 and $200 \mathrm{mg}$ ) that were intended to yield 'low but discernible' and 'moderate but well-tolerated' effects. Although we believe the lower dose achieved its intended effect, the higher dose may have resulted in more side-effects than would have been optimal. Although the ROI results reported in this study remained largely unchanged when sleepiness, dizziness, and reaction time were included as covariates, additional research with slightly lower doses should also be considered. Also, this study investigated neural effects of acute PGB administration. Although PGB clinical trials have reported symptom reduction within 1 week (Feltner et al, 2003; Lydiard et al, 2010) or even as early as $4 \mathrm{~h}$ post-administration (Feltner et al, 2003), it is possible neural mechanisms of acute PGB may differ from those of chronic PGB treatment. Future investigations regarding neural effects of sub-chronic PGB could be useful in extending the current findings. A strength of this study is that it examined the effects of different doses of PGB as compared with placebo in the same group of subjects. However, this could also be considered a limitation in that it required repeated administration of the same anticipation paradigm and therefore could have been influenced by habituation or sensitization effects. Although the ROI results reported remained largely unchanged when including session as a covariate, there remains the potential that repeated testing influenced results. Additionally, this study included healthy control subjects without diagnoses of anxiety disorders. We would expect that individual's with anxiety disorders would display greater differential activation in the ROIs during the anticipation task, as indicated in previous studies (Simmons et al, 2006, 2008). Owing to this, we would expect that the effects of PGB on activation within these regions may be even more pronounced than in this study. However, it is also possible that PGB's mechanisms differ depending on the psychological state of the individual. Future research investigating PGB effects on neural activation of anxiety disorder patients could help to determine the generalizability of current findings to clinical populations and could examine the relationship of such acute neural mechanisms to treatment outcome.

\section{CONCLUSIONS}

The current investigation provides evidence that PGB may share common neural mechanisms with SSRIs and benzodiazepines, namely the attenuation of insula and amygdala activation during affective processing. However, PGB also exhibited effects that have not been reported for other anxiolytics, including enhanced activation in the ACC. The neural effects of PGB did not seem to be due to changes in CBF as measured by ASL or to objective or subjective behavioral measures. Accumulating evidence would suggest that attenuation of insula and amygdala activation during anticipatory or emotional processing may represent an important biomarker for anxiolytic effects across various drug classes. fMRI examination of the neural effects of novel agents with anxiolytic potential could help test the viability of using such fMRI paradigms to predict anxiolytic efficacy.

\section{ACKNOWLEDGEMENTS}

This research was funded by through a grant (MH075792) from the National Institute of Mental Health.

\section{DISCLOSURE}

Robin Aupperle, PhD, Lakshmi Ravindran, MD, Dharol Tankersley, PhD, Taru Flagan, BS, Murray Stein, MD, and Martin Paulus, MD do not report any conflicts of interest related to this paper. Dr Stein has received compensation as a consultant for various companies involved in pharmaceuticals for psychiatric disorders (see full listing of disclosures below), including Pfizer, which distributes Lyrica (PGB). Dr Aupperle receives or has in the past 3 years: salary/funding from the VA San Diego Healthcare System, and University of Kansas Medical Center. Dr Ravindran receives or has in the past 3 years: salary/ funding from the VA San Diego Healthcare System, University of California-San Diego, and University of Toronto. Dr Tankersley receives or has in the past 3 years: salary/funding from Duke University, University of California-San Diego, and Baylor University. Ms Flagan receives or has in the past 3 years received: salary/funding from the University of California - San Diego. Dr Simmons receives or has in the past 3 years: salary/funding from the VA San Diego Healthcare System and the University of 
California-San Diego. Dr Stein receives or has in the past 3 years: research funding from Department of Veterans Affairs; US Department of Defense; Eli Lilly and Company; GlaxoSmithKline; Hoffmann-La Roche; National Institute of Mental Health. He has been a paid consultant for: AstraZeneca; Bristol-Myers Squibb; Comprehensive NeuroScience; Forest Laboratories; Jazz Pharmaceuticals; Johnson \& Johnson; Pfizer; Sepracor. He also receives compensation for his work as an editor with Up-to-Date, and Wiley (Depression and Anxiety). Dr Paulus receives or has in the past 3 years: salary/funding from the San Diego VA Healthcare System and the University of CaliforniaSan Diego; GlaxoSmithKline; Hoffmann-La Roche.

\section{REFERENCES}

Akerstedt T, Gillberg M (1990). Subjective and objective sleepiness in the active individual. Int J Neurosci 52: 29-37.

Anderson AK, Christoff K, Stappen I, Panitz D, Ghahremani DG, Glover G et al (2003). Dissociated neural representations of intensity and valence in human olfaction. Nat Neurosci 6: 196-202.

Anderson IM, Del-Ben CM, Mckie S, Richardson P, Williams SR, Elliott $\mathrm{R}$ et al (2007). Citalopram modulation of neuronal responses to aversive face emotions: a functional MRI study. Neuroreport 18: 1351-1355.

Arce E, Miller DA, Feinstein JS, Stein MB, Paulus MP (2006). Lorazepam dose-dependently decreases risk-taking related activation in limbic areas. Psychopharmacology (Berl) 189: 105-116.

Arce E, Simmons AN, Lovero KL, Stein MB, Paulus MP (2008). Escitalopram effects on insula and amygdala BOLD activation during emotional processing. Psychopharmacology (Berl) 196: 661-672.

Asnis GM, Hameedi FA, Goddard AW, Potkin SG, Black D, Jameel $M$ et al (2001). Fluvoxamine in the treatment of panic disorder: a multi-center, double-blind, placebo-controlled study in outpatients. Psychiatry Res 103: 1-14.

Atack JR (2003). Anxioselective compounds acting at the GABA(A) receptor benzodiazepine binding site. Curr Drug Targets CNS Neurol Disord 2: 213-232.

Baldwin DS (2008). Room for improvement in the pharmacological treatment of anxiety disorders. Curr Pharm Des 14: 3482-3491.

Bandelow B, Behnke K, Lenoir S, Hendriks GJ, Alkin T, Goebel C et al (2004). Sertraline $v s$ paroxetine in the treatment of panic disorder: an acute, double-blind noninferiority comparison. J Clin Psychiatry 65: 405-413.

Brawek B, Loffler M, Dooley DJ, Weyerbrock A, Feuerstein TJ (2008). Differential modulation of $\mathrm{K}(+)$-evoked (3)H-neurotransmitter release from human neocortex by gabapentin and pregabalin. Naunyn Schmiedebergs Arch Pharmacol 376: 301-307.

Britton JC, Taylor SF, Sudheimer KD, Liberzon I (2006). Facial expressions and complex IAPS pictures: common and differential networks. Neuroimage 31: 906-919.

Christmas D, Hood S, Nutt D (2008). Potential novel anxiolytic drugs. Curr Pharm Des 14: 3534-3546.

Cloos JM, Ferreira V (2009). Current use of benzodiazepines in anxiety disorders. Curr Opin Psychiatry 22: 90-95.

Cox RW (1996). AFNI: software for analysis and visualization of functional magnetic resonance neuroimages. Comp Biomed Res 29: $162-173$.

Craig AD (2009). How do you feel-now? The anterior insula and human awareness. Nat Rev Neurosci 10: 59-70.

Craske MG, Rauch SL, Ursano R, Prenoveau J, Pine DS, Zinbarg RE (2009). What is an anxiety disorder? Depress Anxiety 26: 1066-1085.

Critchley HD, Wiens S, Rotshtein P, Ohman A, Dolan RJ (2004). Neural systems supporting interoceptive awareness. Nat Neurosci 7: 189-195.
Davidson JR, Bose A, Korotzer A, Zheng H (2004). Escitalopram in the treatment of generalized anxiety disorder: double-blind, placebo controlled, flexible-dose study. Depress Anxiety 19: 234-240.

Davidson JR, Potts N, Richichi E, Krishnan R, Ford SM, Smith R et al (1993). Treatment of social phobia with clonazepam and placebo. J Clin Psychopharmacol 13: 423-428.

Davis M, Whalen PJ (2001). The amygdala: vigilance and emotion. Mol Psychiatry 6: 13-34.

Del-Ben CM, Deakin JF, Mckie S, Delvai NA, Williams SR, Elliott R et al (2005). The effect of citalopram pretreatment on neuronal responses to neuropsychological tasks in normal volunteers: an FMRI study. Neuropsychopharmacology 30: 1724-1734.

Dooley DJ, Taylor CP, Donevan S, Feltner D (2007). Ca2+ channel alpha2delta ligands: novel modulators of neurotransmission. Trends Pharmacol Sci 28: 75-82.

Feltner D, Wittchen HU, Kavoussi R, Brock J, Baldinetti F, Pande AC (2008). Long-term efficacy of pregabalin in generalized anxiety disorder. Int Clin Psychopharmacol 23: 18-28.

Feltner DE, Crockatt JG, Dubovsky SJ, Cohn CK, Shrivastava RK, Targum SD et al (2003). A randomized, double-blind, placebocontrolled, fixed-dose, multicenter study of pregabalin in patients with generalized anxiety disorder. J Clin Psychopharmacol 23: 240-249.

Fink K, Dooley DJ, Meder WP, Suman-Chauhan N, Duffy S, Clusmann $\mathrm{H}$ et al (2002). Inhibition of neuronal Ca2+ influx by gabapentin and pregabalin in the human neocortex. Neuropharmacology 42: 229-236.

Floyd TF, Ratcliffe SJ, Wang J, Resch B, Detre JA (2003). Precision of the CASL-perfusion MRI technique for the measurement of cerebral blood flow in whole brain and vascular territories. J Magn Reson Imag 18: 649-655.

Fusar-Poli P, Placentino A, Carletti F, Landi P, Allen P, Surguladze $S$ et al (2009). Functional atlas of emotional faces processing: a voxel-based meta-analysis of 105 functional magnetic resonance imaging studies. J Psychiatry Neurosci 34: 418-432.

Garavan H, Pendergrass JC, Ross TJ, Stein EA, Risinger RC (2001). Amygdala response to both positively and negatively valenced stimuli. Neuroreport 12: 2779-2783.

Gee NS, Brown JP, Dissanayake VUK, Offord J, Thurlow R, Woodruff GN (1996). The novel anticonvulsant drug, gabapentin (neurontin), binds to alpha-2-delta subunit of a calcium channel. J Biol Chem 271: 5768-5776.

Harmer CJ, Mackay CE, Reid CB, Cowen PJ, Goodwin GM (2006). Antidepressant drug treatment modifies the neural processing of nonconscious threat cues. Biol Psychiatry 59: 816-820.

Hill MN, Gorzalka BB (2009). The endocannabinoid system and the treatment of mood and anxiety disorders. CNS Neurol Disord Drug Targets 8: 451-458.

Hindmarch I, Trick L, Ridout F (2005). A double-blind, placeboand positive-internal-controlled (alprazolam) investigation of the cognitive and psychomotor profile of pregabalin in healthy volunteers. Psychopharmacology (Berl) 183: 133-143.

Hoffman EJ, Mathew SJ (2008). Anxiety disorders: a comprehensive review of pharmacotherapies. Mt Sinai J Med 75: 248-262.

Jorstad-Stein EC, Heimberg RG (2009). Social phobia: an update on treatment. Psychiatr Clin North Am 32: 641-663.

Kasper S, Stein DJ, Loft H, Nil R (2005). Escitalopram in the treatment of social anxiety disorder: randomised, placebocontrolled, flexible-dosage study. Br J Psychiatry 186: 222-226.

Kessler RC, Chiu WT, Demler O, Merikangas KR, Walters EE (2005). Prevalence, severity, and comorbidity of 12-month DSMIV disorders in the National Comorbidity Survey Replication. Arch Gen Psychiatry 62: 617-627.

Laakmann G, Schule C, Lorkowski G, Baghai T, Kuhn K, Ehrentraut S (1998). Buspirone and lorazepam in the treatment of generalized anxiety disorder in outpatients. Psychopharmacology (Berl) 136: 357-366. 
Lancaster JL, Woldorff MG, Parsons LM, Liotti M, Freitas CS, Rainey L et al (2000). Automated Talairach atlas labels for functional brain mapping. Hum Brain Mapp 10: 120-131.

Lang PJ, Bradley MM, Cuthbert BN (2008). International Affective Picture System (IAPS): Affective Ratings of Pictures and Instruction Manual. Technical Report A-8. University of Florida: Gainesville, FL.

Lewis PA, Critchley HD, Rotshtein P, Dolan RJ (2007). Neural correlates of processing valence and arousal in affective words. Cereb Cortex 17: 742-748.

Lovero KL, Simmons AN, Aron JL, Paulus MP (2009). Anterior insular cortex anticipates impending stimulus significance. Neuroimage 45: 976-983.

Lydiard RB, Rickels K, Herman B, Feltner DE (2010). Comparative efficacy of pregabalin and benzodiazepines in treating the psychic and somatic symptoms of generalized anxiety disorder. Int J Neuropsychopharmacol 13: 229-241.

McIntosh A, Cohen A, Turnbull N, Esmonde L, Dennis P, Eatock J et al (2004). Clinical guidelines and evidence review for panic disorder and generalised anxiety disorder. In: National Collaborating Center for Primary Care. University of Sheffield/ London: Sheffield.

Mitte K, Noack P, Steil R, Hautzinger M (2005). A meta-analytic review of the efficacy of drug treatment in generalized anxiety disorder. J Clin Psychopharmacol 25: 141-150.

Moroz G, Rosenbaum JF (1999). Efficacy, safety, and gradual discontinuation of clonazepam in panic disorder: a placebocontrolled, multicenter study using optimized dosages. J Clin Psychiatry 60: 604-612.

Morrison SE, Salzman CD (2010). Re-valuing the amygdala. Curr Opin Neurobiol 20: 221-230.

Nitschke JB, Sarinopoulos I, Mackiewicz KL, Schaefer HS, Davidson RJ (2006). Functional neuroanatomy of aversion and its anticipation. Neuroimage 29: 106-116.

Pande AC, Crockatt JG, Feltner DE, Janney CA, Smith WT, Weisler $\mathrm{R}$ et al (2003). Pregabalin in generalized anxiety disorder: a placebo-controlled trial. Am J Psychiatry 160: 533-540.

Pande AC, Feltner DE, Jefferson JW, Davidson JRT, Pollack M, Stein MB et al (2004). Efficacy of the novel anxiolytic pregabalin in social anxiety disorder: a placebo-controlled, multicenter study. J Clin Psychopharmacol 24: 141-149.

Paulus MP, Feinstein JS, Castillo G, Simmons AN, Stein MB (2005). Dose-dependent decrease of activation in bilateral amygdala and insula by lorazepam during emotion processing. Arch Gen Psychiatry 62: 282-288.

Paulus MP, Stein MB (2007). Role of functional magnetic resonance imaging in drug discovery. Neuropsychol Rev 17: 179-188.

Phillips ML, Drevets WC, Rauch SL, Lane R (2003). Neurobiology of emotion perception I: the neural basis of normal emotion perception. Biol Psychiatry 54: 504-514.

Pohl RB, Feltner DE, Fieve RR, Pande AC (2005). Efficacy of pregabalin in the treatment of generalized anxiety disorder: double-blind, placebo-controlled comparison of BID vs TID dosing. J Clin Psychopharmacol 25: 151-158.

Pull CB, Damsa C (2008). Pharmacotherapy of panic disorder. Neuropsychiatr Dis Treat 4: 779-795.

Rack-Gomer AL, Liau J, Liu TT (2009). Caffeine reduces restingstate BOLD functional connectivity in the motor cortex. Neuroimage 46: 56-63.

Rickels K, Pollack MH, Feltner DE, Lydiard RB, Zimbroff DL, Bielski RJ et al (2005). Pregabalin for treatment of generalized anxiety disorder: a 4-week, multicenter, double-blind, placebocontrolled trial of pregabalin and alprazolam. Arch Gen Psychiatry 62: 1022-1030.

Rosen JB (2004). The neurobiology of conditioned and unconditioned fear: a neurobehavioral system analysis of the amygdala. Behav Cogn Neurosci Rev 3: 23-41.

Salinsky M, Storzbach D, Munoz S (2010). Cognitive effects of pregabalin in healthy volunteers: a double-blind, placebocontrolled trial. Neurology 74: 755-761.

Simmons A, Matthews SC, Stein MB, Paulus MP (2004). Anticipation of emotionally aversive visual stimuli activates right insula. Neuroreport 15: 2261-2265.

Simmons A, Strigo I, Matthews SC, Paulus MP, Stein MB (2006). Anticipation of aversive visual stimuli is associated with increased insula activation in anxiety-prone subjects. Biol Psychiatry 60: 402-409.

Simmons AN, Arce E, Lovero KL, Stein MB, Paulus MP (2009). Subchronic SSRI administration reduces insula response during affective anticipation in healthy volunteers. Int J Neuropsychopharmacol 12: 1009-1020.

Simmons AN, Paulus MP, Thorp SR, Matthews SC, Norman SB, Stein MB (2008). Functional activation and neural networks in women with posttraumatic stress disorder related to intimate partner violence. Biol Psychiatry 64: 681-690.

Small DM, Gregory MD, Mak YE, Gitelman D, Mesulam MM, Parrish T (2003). Dissociation of neural representation of intensity and affective valuation in human gustation. Neuron 39: 701-711.

Spielberger C (1983). Manual for the State-Trait Anxiety Inventory In: Consulting Psychologists Press: Palo Alto, CA.

Stein MB, Fyer AJ, Davidson JR, Pollack MH, Wiita B (1999). Fluvoxamine treatment of social phobia (social anxiety disorder): a double-blind, placebo-controlled study. Am J Psychiatry 156: 756-760.

Strigo IA, Matthews SC, Simmons AN (2010a). Right anterior insula hypoactivity during anticipation of homeostatic shifts in major depressive disorder. Psychosom Med 72: 316-323.

Strigo IA, Simmons AN, Matthews SC, Craig AD (2010b). The relationship between amygdala activation and passive exposure time to an aversive cue during a continuous performance task. PLoS One 5: e15093.

Takahashi H, Yahata N, Koeda M, Takano A, Asai K, Suhara T et al (2005). Effects of dopaminergic and serotonergic manipulation on emotional processing: a pharmacological fMRI study. Neuroimage 27: 991-1001.

Van Ameringen M., Mancini C, Patterson B, Simpson W (2009). Pharmacotherapy for social anxiety disorder: an update. Isr J Psychiatry Relat Sci 46: 53-61.

Vaswani M, Linda FK, Ramesh S (2003). Role of selective serotonin reuptake inhibitors in psychiatric disorders: a comprehensive review. Prog Neuropsychopharmacol Biol Psychiatry 27: 85-102.

Windischberger C, Lanzenberger R, Holik A, Spindelegger C, Stein $\mathrm{P}$, Moser $\mathrm{U}$ et al (2010). Area-specific modulation of neural activation comparing escitalopram and citalopram revealed by pharmaco-fMRI: a randomized cross-over study. Neuroimage 49: $1161-1170$

Wise RG, Lujan BJ, Schweinhardt P, Peskett GD, Rogers R, Tracey I (2007). The anxiolytic effects of midazolam during anticipation to pain revealed using fMRI. Magn Reson Imag 25: 801-810.

Wong EC, Buxton RB, Frank LR (1998). Quantitative imaging of perfusion using a single subtraction (QUIPSS and QUIPSS II). Magn Reson Med 39: 702-708.

Supplementary Information accompanies the paper on the Neuropsychopharmacology website (http://www.nature.com/npp) 